\title{
Prevalence of Multiple Sclerosis in Canada: A Systematic Review
}

\author{
Alexandre Y. Poppe, Christina Wolfson, Bin Zhu
}

\begin{abstract}
Background: Studies of the prevalence of multiple sclerosis (MS) in Canada have generally been isolated to specific regions. Given the importance of multiple sclerosis as a cause of disability in adults, a comprehensive review of Canadian MS prevalence examining current data, interregional variation, deficiencies in knowledge and frontiers for research is timely. Methods: A systematic review of all studies addressing the prevalence of MS in Canada or regions within Canada, published in English or French since 1985, was conducted. Studies were identified using MEDLINE, EMBASE and bibliographic review. Ten studies were evaluated for methodological rigour and a test of heterogeneity across studies was performed and a measure of consistency $\left(R^{2}\right)$ estimated. Results: Studies were generally of high quality. Nine were restricted to regions witbin Canada and one provided an estimated national prevalence based on self-reported cases. All reported a high prevalence (>50 per 100000). Latitude and longitude gradients were not striking while assessment of heterogeneity confirmed that regional differences were unlikely to be the result of sampling variability. Conclusions: This review confirms Canada as a country of very high MS prevalence and it is the first study to demonstrate that variation in regional estimates represents true differences in prevalence within Canada. Avenues for future MS prevalence research, including adoption of a national MS registry, arc proposed.
\end{abstract}

RÉSUMÉ: Revue systémutique de la prévalence de la scléruse en plaques au Canada. Contexte : Lcs cludes de prévalence de la sclérose en plaques (SEP) au Canada ont généraiement porté sur des régions spécifiques du pays. Étant donné l'imporlance de la SEP comme cause d'invalidité chez les adultes, il est opportun de réviser la prévalence de la SEP au Canada en examinant les données actuelles, la variation interrégionale, les lacunes et les avenues de recherche. Méthodes : Nous avons révisé systématiquement toutes les études pertant sur la prévalence globale ou régionale de la SEP au Canada, publiées en anglais ou en françגis depuis 1985. Nous avons utilisé MEDLINE, EMBASE et une revue bihliographique pour identifier les ćtudes. Nous avons évaluê la rigueur méthodologique de dix études, ainsi que l'hétérogénéité entre les études el esstimé la consistance intene des études. Résultats : Les ćtudes étaìnt gênéralement de bonne qualité. Neuf des études étaient des études régionales et une estimait la prévalence nationale à partir de cas autorapportés. Toutes ces études rapportaient une prévalence élevée $(>50$ par 100000$)$. Un gradient de tatitude ou de longitude n'êtait pas ćvident ct l'évaluation de l'hétérogénéité a confitmé que des différences régionales n'ćtaient vraiscrnblablement pas le résultat de la variabilité de l'échantillonıage. Conclusions : Cette étude confîme que la prévatence de la SEP est très élevés au Canada. C'cst la première étude à démontrer que la variation entre les estimations régionales réprésente des différences réelles dans la prévalence entre différentess régions du Canada. Nous proposonss des avenues de recherche pour les études futures sur la prévalence de la SEP, dont la constitution d'un registre national de la SEP.

Can. J. Neurol. Sci. 2008; 35; 593-601

Multiple sclerosis (MS) is a chronic illness affecting the central nervous system. ${ }^{I}$ Through an inflammatory autoimmune process, there is injury to both myclin and axons resulting in myriad clinical features, including motor weakness, sensory disturbances, visual loss, gait ataxia, sphincter dysfunction and cognitive changes.! While the etiology of multiple sclerosis remains unknown, current evidence suggests an interplay between environmental and genetic factors. ${ }^{1,2}$ Epidemiological studies of MS have demonstrated geographic and demographic variability in both prevalence and incidence.' These results have in turn contributed to hypothesis gencration with regard to MS etiology.

The existing literature suggests that Canada is an area of high MS prevalence ${ }^{3-15}$ Canada is a vast nation comprised of ten provinces and three territorics and lics at latitude $60 \mathrm{~N}$ and longitude $95 \mathrm{~W}$. It has a population of $32,805,041$, of which $70 \%$ is betwecn 15 and 64 years of age. ${ }^{16}$ Two-thirds of the population is concentrated in urban centres and, while ethnically diverse in

Fronl the Department of Epidemiology \& Biostaristics. Departunent of Medicine (CW, BZ), McGill University, Allan mermorial Instilulc, Montreal, Quebsc: Depastment of Clinical Neurasciences (AYP), Fouthills Medical Centre, Caldary. Alberla, Carada

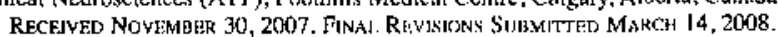
Correspondence to: Alexandrc $Y$, Puppe, Department of Clinical Neurosciences, Foothills Medical Centre, $140329 \mathrm{th}$ Stret, Calgary, Alberta, T2N 2T9, Cadada. 
many of these centres, most inhabitants are primarily of Caucasian European ancestry (over $60 \%$ French or British descent) ${ }^{16}$ An impontant aboriginal population also resides in Canada although few studies have addressed MS prevalence in this population group. ${ }^{17-20}$ Access to healthcare is universal and renders relatively uniform the opportunity for diagnosis and treatment of diseases across the country.

Having accurate figures for MS prevalence in Canada is important in ascertaining the true burden of disease in the country. This in furn can help guide the allocation of research efforts and allow for more precise estimates of the economic weight the disease carries. In addition, knowledge of the current prevalence of MS in Canada would allow for an cvaluation of temporal trends in prevalence as well as an estimation of the impact of any future interventions or events that may affect the prevalence or, indeed, the incidence of MS. There arc challenges in comparing and combining results from existing studies due to differences in case ascertainment, age distribution, ethnic diversity and possible changes in prevalence over time. Neverthcless, the potential utility of systematically reviewing the existing prevalence data and determining whether a synthesis of these data is possible, justifies the exercise.

\section{METHONS \\ Identification of Studies}

This systematic review was designed in accordance with the guidelines outlined by the Meta-Analysis of Observational Studies in Epidemiology recommendations. ${ }^{21}$ Searches of the medical literature (1965-October 2005) were conducted using MEDLINE with the broad subject headings "multiple sclerosis" and "Canada", the latter as an exploded term. The search was conducted for articles written in French or English. A total of 228 references were found. Because single-database searching may have limited yield, the same search was conducted using EMBASE, but this provided no additional references. ${ }^{22}$ Titles were revicwed, potentially relevant articles were retained and full text oblained. The bibliographies of these articles were then hand scarched for additional references. A total of 21 studies were found, four through bibliographic review and two through one author's own files (CW). Six studies werc published before 1985 and excluded. ${ }^{23-28}$ Of the remaining 15 studies, one was

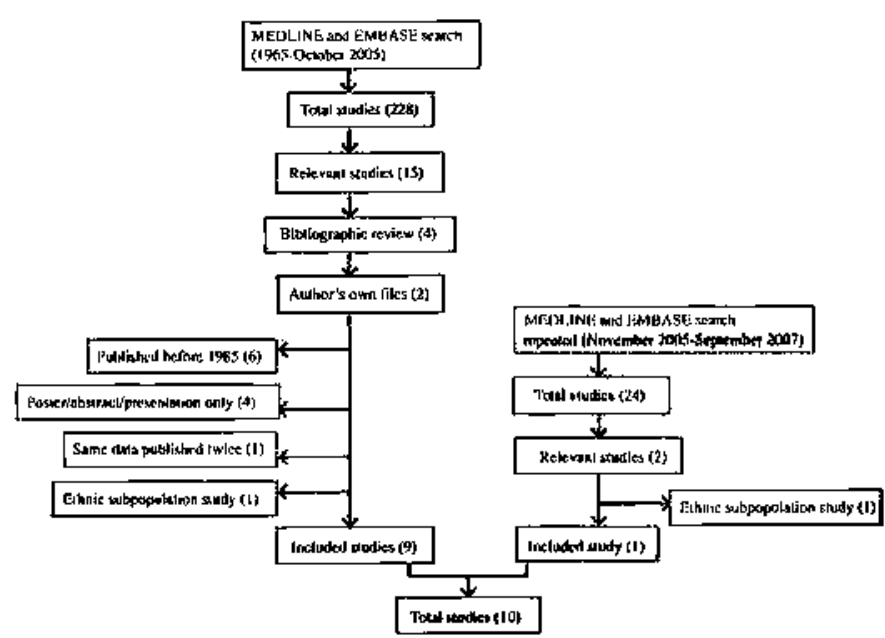

Figure 1: Flow diagram of study selection.

available only as an abstract, two as posters and one as a presentation; these were not included in the formal review. 4.7.11,19 In one case, data were published iwice, once as a poster and once as a paper and only the paper was included." Finally, one targeted an ethnic subpopulation and was excluded. ${ }^{18}$ This process yielded nine papers for inclusion in our systematic revicw (Figure 1 ).

The same search strategy was repeated using MEDLINE for the period from November 2005 to Scptember 2007 to identify any additional relevant studies published during that period. This search yiclded 24 results. A review of titles and abstracts confirmed two potentially relevant papers. ${ }^{15,2 t)}$ One included data from a study available only as a presentation prior to November $2005 .{ }^{19,20}$ As it was devoted to a special subpopulation, this study was not included. The second study ${ }^{15}$ was included, bringing the total number of studies to ten (Table 1).

\section{Table 1: Studies included in systematic review}

\begin{tabular}{|c|c|}
\hline $\begin{array}{l}\text { Refercnce } \\
\text { No. }\end{array}$ & Reference \\
\hline 10 & Sweeney VP et al. Prevalence of nultiple scleresis in Britisl/ Columbia Cern J Neurol $S_{c i}$ 1986; 13:47-51. \\
\hline 6 & Jryse-Phillips WEM et al. The incidence and prevalence of multiple sclerosis in Newtound land and Labrador, 1960-1984. Amn Neurol 1986; $20: 323-328$. \\
\hline 4 & 1Fader WJ et al. Epideniology of multiple sclerosis in London and Midslesex County, Ontatio, Canada. Neurology 1988; 38:617-621. \\
\hline 9 & Warten $S$ and Warren KG. Prevalence of inuliple sclesosis in Barthead County, Alberta. Canada. Can J Neurol Sci 1992; 19:72-75. \\
\hline 12 & Warren S and Warren KG. Prevalence, incidence, and characteristics of multiple sclerosis in Westiock County, Alberta, Canisla Ncurnlogv 1993; 42:1760-1763. \\
\hline 11 & KIcin GM et al. A prevalence study of imultiple sclerosis in the Crowsnest Pass region of southern Alberta. Can J Neurol Sci 1994:21:262-265. \\
\hline 14 & Svenson LW et al. Regional variatiens in the prevalence rates of multiple sclerosis in the province of Alberta, Canada, Neuroepidemiology 1994; 13:8-13, \\
\hline 5 & Sloka IS et al, Fitcidence and prevalence of multiple sclerosis in Newfoundland and Labrador. Can J Neurol Sci 2005; 32:37-42. \\
\hline 13 & Bcck CA et al. Regional variation of multiple scierosis prevalence in Camada. Multiple Sclevosis $2005 ; 11: 516.519$. \\
\hline 15 & Hader WJ el al. lncidence and prevalence of mulliple sclemsis in Saskatoon, Saskatchewan. Netrology $2007 ; 69: 1224-1229$. \\
\hline
\end{tabular}




\section{Inclusion Criteria}

Inclusion criteria were broad and encompassed any study that reported primary data on MS prevalence in Canada, or regions therein, published in French or English between January 1985 and September 2007. All studies meeting inclusion criteria were published in English. We found two studies from the same group examining MS prevalence in the same territory (Newfoundland and Labrador) at different time points. ${ }^{56}$ Both studies were included for analysis.

\section{Exclusion Criteria}

We excluded genetic epidemiological studies looking at prevalence of MS in family members of affected probands. ${ }^{29.30}$ Studies devoted to special subpopulations (such as First Nations or the Hutterites) were excluded. ${ }^{18-20}$ Economic burden and mortality studies were also excluded as were data presented only in posters, abstracts, letters or presentations.

\section{Data Extraction}

Once accepted for inclusion, studies were assessed using a quality assessment tool designed for studies of prevalence and relevant information was extracted using a data abstraction grid. Quality assessment parameters included proper definition of study population characteristics, method of case ascertainment (i.e. chart review, patient examination), reproducibility of case definition, clear statement of prevalence dates and description of statistical analyses used to derive prevalence figures. Check boxes permitted differentiation between "Very Good", "Good" and "Poor" for each quality assessment parameter. "Very Good" was used when the parameter was addressed completely, "Good" when it was addressed but incompletely, and "Poor" when it was not addressed at all. Whichever descriptor was applied most often to a particular study determined the overall quality rating for that study. Two authors (AYP, CW) reviewed the studies independently and when necessary, disagreements were resolved by consensus.

Data abstraction included information about the study (authors, year of publication, region studied), information about study methods (study population, case definition, case ascertainment) and study results (crude prevalence rates, ageand sex-specific prevalence and other relevant results).

\section{Data Analyses}

Extracted data concerning study methodology and results were tabulated (Table 2). Several studies examined both prevalence and incidence of MS but given the aim of this review, only prevalence values were extracted. All studies provided prevalence as number of cases per 100000 population and all but two provided confidence intervals. Age- and sex-standardization were not reported in all studies.

A test for heterogeneity across studies was conducted to test the null hypothesis that all studies are estimating the same parameter.' Rejecting this null hypothesis would support the notion that there is in fact true variation in MS prevalence between the study populations not due to sampling error. Higgins et al provide a measure of consistency across studies that is derived from the $Q$ statistic and is not dependent on the number of studies included for comparison. ${ }^{31}$ This measure, $P^{2}$ is calculated as $P=100 \%(Q-d f) / Q$, where $\mathrm{df}=$ degrees of freedom $=$ number of studies -1 . The value is expressed as a value between 0 and $100 \%$, where 0 indicates no heterogeneity and increasingly larger values suggest increasing heterogeneity. Generally, an $I^{2}$ of less than $25 \%$ indicates low heterogeneity, $25 \%$ to $50 \%$, moderate heterogeneify and over $50 \%$, high heterogeneity, ${ }^{31,32}$

Given that the data are derived from different populations at different time points, pooling of these data may mask regional and temporal differences. A high degree of inconsistency across studies further argues against statistical pooling of results. ${ }^{31,32}$

\section{Results}

\section{Study characteristics}

Ten studies met inclusion criteria (Table 1). Publication dates ranged from 1986 to 2007 and all studies were considered of "Good" or "Very Good" quality. Four studies examined provincial MS prevalence, five examined prevalence within smaller geopolitical regions (cities or counties) and one examined national prevalence and prevalence within larger subdivisions of Canada. Of the provincial and regional studies, four were from Alberta, two from Newfoundland and Labrador, one from Saskatchewan, one from Ontario and one from British Columbia (Figure 2). The number of identified cases ranged from 7 to 5548 (median $=274.5$ ) and population denominators ranged from 6912 to 2791398 (median $=742592$ ). It is likely that the same cases may have been "double counted" in separate studies of the same region. All studies estimated pointprevalence although two did not provide an exact prevalence date. ${ }^{13,14}$

Cases were ascertained in a similar manner in all but two studies, that is, through MS registries, MS clinic charts, neurologists' files, hospital admissions, MS society documents, mailing lists and other physicians. Patients were examined by a neurologist-investigator in only three of the ten studies, $4,9,12$ These methods are generally supported by a recent study on the thoroughness of MS case ascertainment in small communities. ${ }^{33}$ Interrater reliability for the diagnosis of MS was not reported, but agreement on such a diagnosis among neurologists is presumably high given defined diagnostic criteria. Comparisons of Poser and 2001 MacDonald criteria have suggested similar rates of MS diagnosis. ${ }^{33,34}$ One of the studies used billing data from the Alberta Health Care Insurance Plan (AHCIP) (ICD-9 code 340$).^{14}$ The national study was based on self-report of an MS diagnosis among respondents to the Canadian Community Health Survey (CCHS). ${ }^{13}$

The studies in this review span 20 years and earlier studies predate the routine inclusion of MRI criteria in the diagnosis of MS. Of those eight studies not relying on billing data or selfreport, the two oldest studies utilized Schumacher criteria (1965), ${ }^{6,10}$ two used modified Schumacher criteria (no age criterion), ${ }^{4,11}$ three used Poser criteria (1983) $)^{5,9.12}$ and one ${ }^{15}$ used a combination of these, including the more recent MRI-based McDonald criteria ${ }^{35,36}$ 
THE CANADIAN JOURNAL OF NEUROLOGICAL SCIENCES
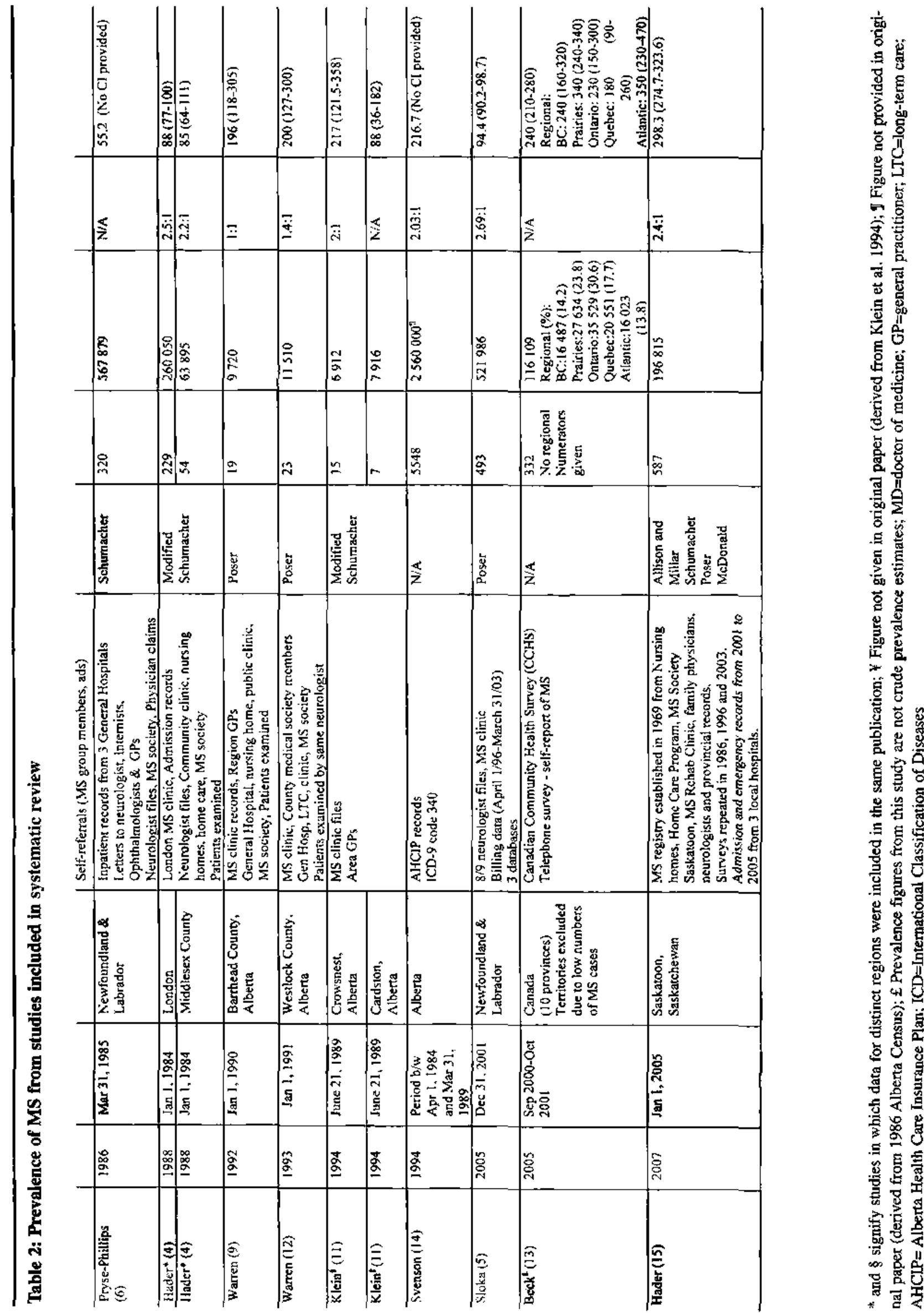


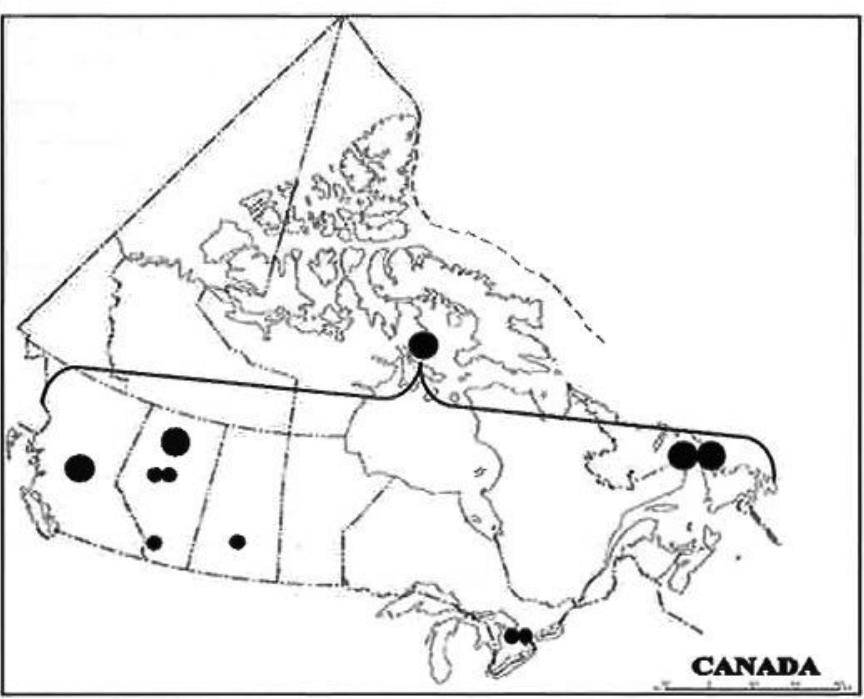

Figure 2: Geographic distribution of MS prevalence studies in Canada (larger circles: national or provincial studies, smaller circles: city or county studies).

\section{Results by region}

\section{British Columbia}

British Columbia (BC) is Canada's westernmost and third most populated province. Central latitude and longitude are $55 \mathrm{~N}$, $125 \mathrm{~W}$ and the population is primarily concentrated in Vancouver and its surrounding areas. One study found a crude prevalence of MS in BC of 93.3 per 100000 on prevalence day July $1,1982 . .^{10}$ When adjusted to the Canadian population, the prevalence was 91 per 100000 . A total of 2596 cases were found but no denominator (i.e. population of BC) or confidence interval was provided in the original paper. However, in a subsequent study, Klein et al. calculated the confidence interval to be 89.42 to 96.58 per 100000 assuming a population of $2791398 .{ }^{11}$ Female prevalence was higher at 126.4 per 100000 compared to 59.8 per 100000 for males. This study used Schumacher criteria to classify cases as definite/probable MS and relied on neurologist chart reviews, communication with other physicians, long-term care facilities and self-referrals to identify cases.

The study by Beck et al also provides estimates for BC, suggesting a much higher prevalence of 240 per $100000(95 \%$ CI $160-320$ ). This study used data from a national population health survey (CCHS) conducted by telephone. Identification of cases was based on self-report in answer to the question "We are interested in long-term conditions that have...been diagnosed by a health professional. Do you have multiple sclerosis?"13 Diagnoses were not confirmed through chart review, physician contact or patient encounter. Because of small samples in the territories, only respondents living in one of the ten provinces were included in the analysis. A total of 116109 respondents out of 131535 were over 17 years-old and responded to the survey question pertaining to MS, making them eligible for analysis of MS prevalence.

\section{Prairie provinces}

Alberta, Saskatchewan and Manitoba comprise Canada's "Prairie provinces". Alberta and Saskatchewan are discussed below but we found no published data exclusive to Manitoba meeting our inclusion criteria. Two studies of MS prevalence in Winnipeg, Manitoba's capital, were published prior to 1985 , one in 1953 and the second in $1964 .^{23,26}$

The Prairie provinces were considered as a single territory in the Beck et al study and a prevalence of 340 per $100000(95 \%$ CI: 240-340) was estimated. ${ }^{13}$

\section{Alberta}

Alberta is the province for which there exist the most data regarding MS prevalence. In fact, four of the ten studies reviewed pertain to this westernmost Prairie province whose central geographical coordinates are $55 \mathrm{~N}, 115 \mathrm{~W}$. The population is clustered primarily in two urban centres, Calgary and Edmonton, although there is also significant rural and aboriginal representation.

A study in Barrhead County, a rural area northwest of Edmonton, found a prevalence of 196 per 100000 (95\% CI: 118305 ) in $1990 .{ }^{9}$ The authors of this study also examined MS prevalence in 1991 in a neighbouring region, Westlock County. ${ }^{12}$ The results were standardized to the population of Alberta from the 1986 census yielding a figure of 200 per 100000 (95\% CI: 127-300).

The Crowsnest Pass region and Cardston and southern Alberta were studied in 1989 using MS society lists and patient files from general practitioners for case ascertainment. ${ }^{11}$ Modified Schumacher criteria were used and a prevalence of 217 per 100000 (95\% CI: 121.5-358) was found for Crowsnest and 88 per 100000 (95\% CI: 36-182) was found for Cardston.

Avoiding the statistical limitations of small population studies, Svenson et al. used data from the Alberta Health Care Insurance Plan collected between April 1st, 1984 and March 31st, 1989 to estimate MS prevalence for the province of Alberta. ${ }^{14}$ The AHCIP contains records of all registered residents, although the use of this database for determining MS prevalence has not been fully validated. The MS cases were identified using the diagnostic code ICD-9 No. 340. In total, 5548 cases were identified, yielding a mean crude prevalence of 216.7 per 100000 with a female to male ratio of $2.03: 1$. The use of claims administrative data may underestimate true MS prevalence given the absence of early, undiagnosed cases and patients unseen by a physician within the studied five-year period, both of which likely exceed the number of misdiagnosed cases.

The Beck et al study further examined MS prevalence in Alberta and used AHCIP data to confirm the validity of the CCHS results. ${ }^{13}$ Within the AHCIP, cases were identified if patients had been assigned a diagnostic code for MS twice between 1991 and 2001. Using this method and a total population of 2.97 million, a prevalence of 386 per 100000 (95\% CI: 377-394) was found.

\section{Saskatchewan}

Three MS prevalence studies in Saskatoon $\left(52^{\circ} 10^{\circ} \mathrm{N}\right.$, $106 \mathrm{~W})$, this province's largest city, have been published. The 
first in 1982, and not formally included in our review, reported a period prevalence of 135 per 100000 between 1970 and $1979 .{ }^{28}$ This valuc was upwardly revised in 1999 using MS clinic registry data as well as medical records and provincial resources. ${ }^{7}$ The most recent study estimated MS prevalence on January lst, 2005. ${ }^{15}$ The authors ascertained cases using an MS rcgistry started in 1969 as well as information from nursing homes, home care programs, the MS Society of Saskatoon, family physicians, neurologists and provincial records. Medical records for admissions and emergency department visits between 2001 and 2005 were also screened. Uniform diagnostic criteria were not applied to all patients since different criteria have been used over time to admit patients to the MS registry. On prevalence day, 587 living cascs were identified. With a city population of 196815 , a crude prevalence figure of 298.3 per $100000(95 \%$ CI 274.7 to 323.6$)$ was calculatcd. A female to male ratio of 2.4:1 was found and when age- and sex-adjusted to the Canadian 2001 population, the prevalence was 329 per 100 000 . The authors similarly standardized their results to the world 2000 population ( 240.4 per 100000 ), as has been suggested by others. ${ }^{37}$ Such standardized figures allow for more meaningful comparisons between regional prevalence studics than do crude prevalence values.

Claims of a cluster-focus of MS in the hamlet of Henribourg, Saskatchewan due to a postulated common environmental exposure have also been extensivcly studied..$^{38}$ The existence of genuine MS clusters or epidernics has been questioned and the contribution of such studies to estimates of "background" MS prevalence in the population is likely limited.'

\section{Onsario}

Ontario is Canada's most populated province with central coordinates $50 \mathrm{~N}$ and $86 \mathrm{~W}$. The population is primarily urban and concentrated in a corridor extending from Windsor to Kingston. Two studies published prior to 1985 were not included in our review: a survey of MS patients in Kingston in 1959 and in Otlawa in $1977 .^{24,27}$ Only one study has been published since 1985 examining MS prevalence in Ontario alone. ${ }^{4}$ This study examined both prevalence and incidence of MS in London and nearby rural Middlesex County, both in southwestem Ontario. Case identification included using MS clinic records as well as review of local hospital admissions, long-term care facilities, home care programs and MS Society membership lists. Identified patients were examined by the authors. Crudc prevalence for definite MS was 88 per 100000 (95\% Cl: 77-100) for London and 85 per 100000 ( $95 \%$ CI: 64-111) for Middlesex County. When adjusted to the 1981 Canadian population, a prevalence of 90 per 100000 was found for clinically definitc cases in London. Higher prevalence was noted among women, particularly those in the $35-44$ age group.

The more recent CCHS study found a prevalence of 230 per $100000(95 \% \mathrm{CI}: 150-300)$ for Ontario as a whole.

\section{Quebec}

Quebec has central coordinates $52 \mathrm{~N}$ and $72 \mathrm{~W}$, and despite bcing Canada's second-most populous province, there is surprisingly little data regarding the prevalence of MS in this region. In fact, no prevalence studies isolated to Quebec as a whole or Quebec communities were identified in our literaturc search. Qucbec's population resides primarily in the southwestern region between Montreal and Quebec City and is also ethnically different in that the large majority of its inhabitants are of French ancestry. The only provincial prevalence information available comes from the CCHS study in which a prevalence of 180 per 100000 (95\% CI: $90-260$ ) was found, making it the region with the lowest MS prevalence in Canada using that methodology.

\section{Atlantic Provinces}

The Atlantic provinces on Canada's eastern coast inciude Newfoundland and Labrador, as well as New Brunswick, Nova Scotia and Prince Edward Island. Overall, these provinces are less populated than central and western Canada and are composed primarily of people of British, Irish and Scottish ancestry with both a rural and urban distribution. Other ethnic groups, including Acadians and Natives also contribute to the local demography.

The Atlantic provinces were examined as a group in the Beck et al study, in which a prevalence of 350 per $100000(95 \% \mathrm{CI}$ : $230-470$ ) was found. ${ }^{13}$ This was the highest regional prevalence identified in the CCHS, however this figure is much higher than that found in those studics specifically examining Nova Scotia and Newfoundland and Labrador.

\section{Newfoundland and Labrador}

The island of Newfoundland lies between latitudes 46 and $52 \mathrm{~N}$ and longitudes 52 and $59 \mathrm{~W}$ and Labrador is situated between 52 and $61 \mathrm{~N}$ and 56 and $67 \mathrm{~W}$. On the island of Newfoundland the population is primarily clustered near St. John's and in large part, inhabitants are of southern English and Irish descent.

Two studies conducted by the same group examined MS prevalence in this territory at two different time points, 1985 and $2001 .^{5,6}$ The authors propose that the more recent study is more likely to accurately reflect true prevalence because of better case ascertainment and more uniform diagnostic capabilities throughout the province. The earlier study identified cases using in- and outpatient medical records as well as MS society membership lists and physician claims data available from 1983 onwards. Prevalence day was March 31st, 1985 and 32 cases with definite or probable MS by Schumacher criteria were identified, yielding a crude prevalence of 55.2 per 100000 .

The 2001 study sought to update the previous data and took advantage of billing data using diagnostic codes, files from the only MS clinic in the province and three previously compiled databascs to achieve more thorough case ascertainment. ${ }^{5} \mathrm{~A}$ total of 493 cases were found on prevalence day (December 31st, 2001) using Poser criteria, giving a crude prevalence of 94.4 (95\% CI: $90.2-98.7$ ).

\section{Other Atlantic Provinces}

Other than Newfoundland and Labrador only Nova Scotia has been studied with regards to MS prevalence. One study focusing on Nova Scotia's capital, Halifax, was published in 1960 and excluded from this revicw. ${ }^{25} \mathrm{~A}$ more recent study was also excluded because data were published only as a poster. ${ }^{8}$ In this study, provincial prevalence in 2001 was ascertaincd using records from the only MS clinic in the province in conjunction 


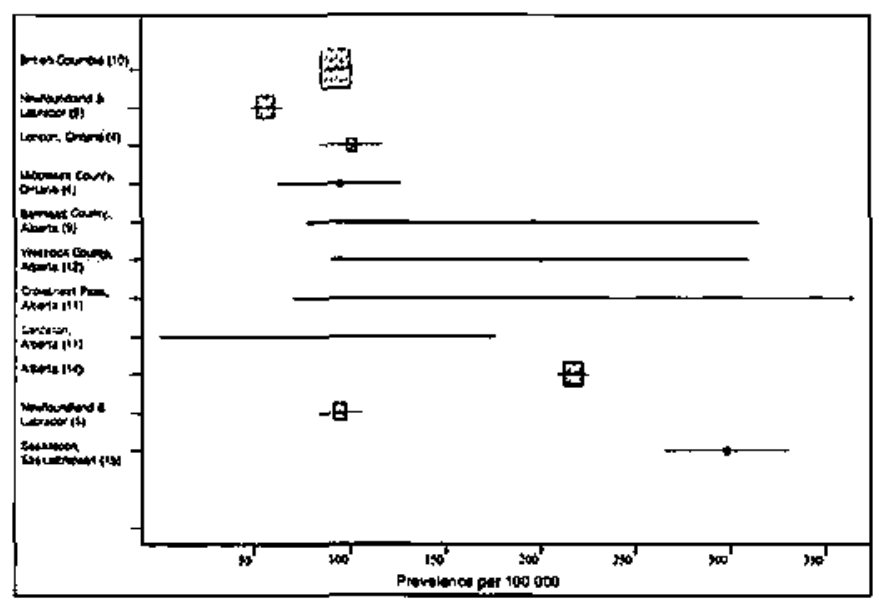

Figure 3: Plot of crude $M S$ prevalence for regions from included studies.

with government administrative databases. ${ }^{8}$ The authors suggest that the best estimate is likely in the range of 200 to 218 per 100000

\section{Canada}

No single study examined national MS prevalence before the Beck et al study. In this study, 332 respondents reported a diagnosis of MS among the $116 \mathrm{I09}$ eligible to participate. This produced a national prevalence of 240 per 100000 ( $95 \%$ CI: 210-280) and this has engendered an upward revision of traditional national MS prevalence figures forwarded in years past.

Prevalence studies have often been compromised by small sample sizes and therefore large, overlapping confidence intervals that raise the possibility of there being no true regional differences within the country (Figure 3). Determining whether finding a single national prevalence for MS is meaningful rests in large part on whether interregional differences are real. If so, then a single national prevalence estimate may in fact underestimate the burden of disease in some Canadian territories, while overestimating it in others.

In addition, although a latitude gradient of MS prevalence has been found in other parts of the world, including the USA, Australia and Italy, nonc could be demonstrated within Canada (Table 3) ${ }^{3}$ Presumably, this is because the large majority of the Canadian population lives within a relatively narrow latitude corridor in the southern part of the country.

\section{Heterogeneity among studies}

For the computation of $f^{2}$ to examine variability, two studies were excluded due to major differences in methodology. ${ }^{13.14}$ Also, the earlier Newfoundland and Labrador study ${ }^{6}$ was excluded from the analysis given that more recent data for that province likely better reflect true MS prevalence. In two other studies, separate data werc provided for neighbouring regions and these were considered as distinct data sets in our analysis.,11 Therefore, nine sets of data were included in the analysis and a
Table 3: Canadian regional MS prevalence estimates from included studies, by latitude and longitude

\begin{tabular}{|c|c|c|c|}
\hline Locstion & 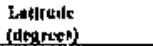 & $\begin{array}{l}\text { Lopelitude } \\
\text { fongregs }\end{array}$ & $\begin{array}{l}\text { Presaleace per } 1000000 \\
\text { dese 디? }\end{array}$ \\
\hline 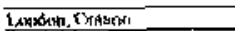 & $4.3 \mathrm{~N}$ & 81\% & $\sqrt{3 \times 1750)}$ \\
\hline 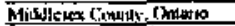 & $4 \mathrm{ST}$ & $81 \mathrm{~W}$ & $85(64.111)$ \\
\hline Crotzsllest V'Yss, Alberta & $49 \mathrm{~N}^{*}$ & & $217(1214-358)$ \\
\hline Sindurat, Althesta & 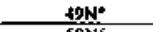 & $113 \mathrm{w}^{\circ}$ & s\$po. 182$)$ \\
\hline 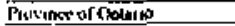 & $\sin S$ & 896168 & $230(150.300)$ \\
\hline 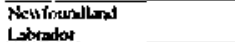 & \begin{tabular}{l|l}
$46.52 \mathrm{~N}$ & $32 \mathrm{NS}$ \\
$52.61 \mathrm{~N}$ &
\end{tabular} & $\begin{array}{l}52-59 \mathrm{~W} \\
\operatorname{San}-67 \mathrm{~W}\end{array}$ & 944 \\
\hline 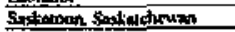 & $\frac{1}{2} \ln N$ & $106 \mathrm{~W}$ & $2983(2747.3236)$ \\
\hline Province of outhax & SANB & 72w18 & $16000-2(0)$ \\
\hline 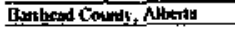 & $\sin$ & $\ln \mid \frac{10}{4}$ & $18(19-\overline{3}(5)$ \\
\hline Wonlack. Albeela & $\operatorname{sen}$ & IINW & $200(1973000)$ \\
\hline Tow'ince of Alketita & $\$ S N^{*}$ & IISSN" & 2167 \\
\hline 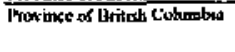 & $35 \mathrm{~N}$ & $125 W$ & $\begin{array}{c}23.3(80.42 .9658) \\
240(160.320)\end{array}$ \\
\hline
\end{tabular}

Sestimated geographical centre of territory; "geographical coordinates not provided in paper

high degree of heterogeneity $\left(I^{2}=98.86\right)$ was found with a very large $Q$ statistic: $Q=703.30, \mathrm{df}=8, \mathrm{p}<0.0001$. Studies published more recently generally yiclded higher prevalence estimates.

\section{Discussion}

Several regional studies of MS prevalence have been conducted and suggest wide variation within the country. Our review suggests a range from a low of 55.2 per 100000 in Newfoundland and Labrador to a high of 350 per $100000(95 \%$ CI: $230-470$ ) in the Atlantic provinces. ${ }^{6.13}$ of course, the Newfoundland study has since been repeated and yielded a higher prevalence while the methodology of the CCHS study which has suggested by far the highest prevalence figures to date, differs immensely from the other publications included for review. The $I^{2}$ valuc obtained confirms that the different prevalence estimates in the studies likely constitute true differences. This lends strong credence to the assertion that arriving at a single point estimate of national prevalence is a difficult and possibly misleading enterprise.

It is clear that more recent studies are producing higher prevalence figures than older ones. One might speculate that this reflects an increased incidence of disease, although other explanations are also plausible. In particular, improved case ascertainment via better access to neurologists and diagnostic tests likely explains the increased prevalence found in more recent studies as it did in the later Newfoundland study. Improved medical carc kading to longer life spans among MS patients may also account for this apparent increase in prevalence. Analysis of sex ratios of MS by year of bitth in a longitudinal population based dataset of over 29000 Canadian MS patients (Canadian Collaborative Project on Genetic Susceptibility to Multiple Sclerosis) suggests an increasing ratio of female to male cases. ${ }^{39,40}$ This might imply an increasing disease incidence over the last 50 years, particularly in women, the cause of which may be environmental.

Most prevalence studies reviewed here reported a female to male ratio of approximately $2: 1$, from a low of $1: 1$ in Barrhead County, Alberta to a high of 2.69:1 in Newfoundland and 
Labrador. ${ }^{5,9}$ It should be noted, that unlike incidence, prevalence does not necessarily reflect a true geographic "risk" of developing MS since prevalent cases might tend to migrate to larger centres seeking tertiary medical care. This may falsely increase prevalence figures in metropolitan areas, as suggested by some, ${ }^{15}$ but discounted by others. ${ }^{6}$

However, the regional variation in prevalence remains largely unexplained and raises questions regarding environmental and genetic influences. Given universal, publicly funded healthcare, differential access to diagnosis and treatment should ideally not result in regional ascertainment bias. A trend towards higher prevalence in the west as opposed to central Canada is suggested..$^{13,14}$ Ethnic and migrational differences in persons of European ancestry have been promulgated as possible explanations for the north-south gradient in MS prevalence suggested in American studies. ${ }^{3}$ No such ethnic differences readily explain the regional variation seen in Canada given that the populations of all Canadian provinces are comprised primarily of Caucasians of European ancestry. However, in an Albertan study of parental ancestry of MS patients, non-specific European ancestry was positively correlated with MS, while British ancestry was associated with a reduced risk. ${ }^{41}$ Ethnically distinct groups in Canada have not been widely studied, including First Nation Canadians. However, existing studies of First Nations do suggest a lower prevalence of MS than their Caucasian neighbours with whom they presumably share similar environmental exposures. ${ }^{17-20,41}$ Studies of Germanic Hutterite communities with lower MS prevalence than non-Hutterite Canadians $^{42}$ also support the influence of genetic differences in determining MS prevalence. Multiple sclerosis prevalence in French Canadians, as a genetically and geographically isolated population, has not been studied in any detail.

Genetic susceptibility is well described ${ }^{43}$ and further supported by four prevalence studies which cite a family history of MS in up to $40 \%$ of prevalent cases.,9,12,15 Variation of MS prevalence within countries has been well described in France, Italy and the UK. ${ }^{44,45}$ In these instances, a satisfactory explanation is also still lacking. No robust data yet support environmental toxins, infections or other non-genetic risk factors as a sufficient or necessary cause ${ }^{46}$ Furthermore, genetic differences are also unlikely to be the sole explanation.

As with all systematic reviews, the current study is susceptible to certain limitations. First, such a review can only be as good as those studies included for analysis. Although search parameters were broad, some relevant studies may have been missed or the results of included studies misinterpreted. It is also evident that some regions in Canada are very well studied (i.e. Alberta) while others having greater demographic weight have barely been studied at all (i.e. Quebec). The differences in study methodologies, case definition, population sizes and demographics and the dates the studies were performed all render meaningful comparisons and pooling of data difficult and approximate. The general non-reporting of sex- and agestandardized prevalence figures only further adds to the difficulty in comparing studies. Our analyses of heterogeneity and calculation of confidence intervals relied on the completeness of data published in the original studies.

Despite these limitations, the current review helps consolidate current knowledge of MS prevalence in Canada and confirms that this country has a national prevalence among the highest in the world of at least 100 per 100000 , and likely much higher. It also confirms that the regional variation in prevalence suggested in previous studies is genuine. Perhaps most importantly, it makes evident the gaps in knowledge that still exist concerning Canadian MS epidemiology. Future studies of MS prevalence should use more uniform case definition and ascertainment methods and provide prevalence values standardized to the Canadian population (by age and sex) to facilitate comparisons between regional studies. In addition, values standardized to the world population would help with comparisons between national studies, as has been advocated by others..$^{37,44}$ Canada serves as an ideal territory for the study of MS epidemiology given the high prevalence of disease, regional variation, the presence of a wellestablished community of MS researchers and publicly-funded, universally accessible healthcare. Establishment of a national MS registry, as has been done in Norway, would further strengthen such research efforts. ${ }^{47}$

\section{REFERENCES}

1. Poser CM. The epidemiology of multiple sclerosis: a general overview. Ann Neurol. 1994 Dec;36 Suppl 2:S180-93.

2. Poser CM. The diagnosis and management of multiple sclerosis. Acta Neurol Scand. 2005 Sep;112(3):199-201.

3. Rosati G. The prevalence of multiple sclerosis in the world: an update. Neurol Sci. $2001 \mathrm{Apr}$;22(2):117-39.

4. Hader WJ, Elliot M, Ebers GC. Epidemiology of multiple sclerosis in London and Middlesex County, Ontario, Canada. Neurology. 1988 Apr;38(4):617-21.

5. Sloka JS, Pryse-Phillips WE, Stefanelli M. Incidence and prevalence of multiple sclerosis in Newfoundland and Labrador. Can $\boldsymbol{J}$ Neurol Sci. 2005 Feb;32(1):37-42.

6. Pryse-Phillips WE. The incidence and prevalence of multiple sclerosis in Newfoundland and Labrador, 1960-1984. Ann Neurol. 1986 Sep;20(3):323-8

7. Hader W. The incidence and prevalence of multiple sclerosis in Saskatoon, Saskatchewan: a reappraisal. Neuroepidemiology. 1999;18:327-32.

8. Bhan V, Brown MG, Fisk JD, Sketris I, Stadnyk K, MacKinnonCameron $\mathrm{D}, \mathrm{Li} \mathrm{N}$. Incidence and prevalence of Multiple Sclerosis in Nova Scotia. American Academy of Neurology Annual Meeting, miami, Florida, April 14, 2005. Neurology. 2005; 64 Suppl 1: A320.

9. Warren S, Warren KG. Prevalence of multiple sclerosis in Barrhead County, Alberta, Canada. Can J Neurol Sci. 1992 Feb;19(1): $72-5$.

10. Sweeney VP, Sadovnick AD, Brandejs V. Prevalence of multiple sclerosis in British Columbia. Can J Neurol Sci. 1986 Feb;13 (1):47-51.

11. Klein GM, Rose MS, Seland TP. A prevalence study of multiple sclerosis in the Crowsnest Pass region of southern Alberta. Can J Neurol Sci. 1994 Aug;21(3):262-5.

12. Warren S, Warren KG. Prevalence, incidence, and characteristics of multiple sclerosis in Westlock County, Alberta, Canada. Neurology. 1993 Sep;43(9):1760-3.

13. Beck CA, Metz LM, Svenson LW, Patten SB. Regional variation of multiple sclerosis prevalence in Canada. Mult Scler. 2005 Oct;11(5):516-9.

14. Svenson LW, Woodhead SE, Platt GH. Regional variations in the prevalence rates of multiple sclerosis in the province of Alberta, Canada. Neuroepidemiology. 1994;13(1-2):8-13.

15. Hader WJ LI. Incidence and prevalence of multiple sclerosis in Saskatoon, Saskatchewan. Neurology. 2007;69:1224-9.

16. 2006 Census. Statistics Canada; 2007.

17. Hader W, Feasby T, Rice GPA, Ebers G. Multiple sclerosis in Canadian native peoples. Neurology. 1985;35Suppl 1:300. 
18. Mirsattari SM, Johnston JB, McKenna R, Del Bigio MR, Orr P Ross RT, et al. Aboriginals with multiple sclerosis: HLA types and predominance of neuromyelitis optica. Neurology. 200I Feb 13:56(3):317-23.

19. Warren S, Svenson LW, Warren KG, Metz LM, Patten SB, Schopflocher DP. Incidence of Multiple Sclerosis amound First Nation People in Alberta, Canada. Society for Epidemiologic Research, Toronto, Ontario, June 2005.

20. Warren S SL, Warren KG, Metz LM, Patten SB, Schopflocher DP. Prevalence of multiple sclerosis in First Nations people of Alberta. Can J Neurol Sci. 2007;34(2):175-80.

21. Stroup DF, Berlin JA, Morton SC, Olkin I, Williamson GD, Rennie D, et al. Meta-analysis of observational studies in epidemiology: a proposal for reporting. Meta-analysis of observational studies in epidemiology (MOOSE) group. JAMA. 2000 Apr 19;283 (15):2008-12.

22. Lemeshow AR, Blum RE, Berlin JA, Stoto MA, Colditz GA Searching one or two databases was insufficient for metaanalysis of observational studies. J Clin Epidemiol. 2005 Sep;58(9):867-73

23. Westlund KB, Kurland LT. Studies on multiple sclerosis in Winnipeg, Manitoba, and New Orleans, Louisiana. I. Prevalence; comparison between the patient groups in Winnipeg and New Orleans. Am J Hyg. 1953 May:57(3):380-96.

24. White DN, Wheelan L. Disseminated sclerosis; a survey of patients in the Kingston, Ontario, area. Neurology. 1959 Apr:9(4): 256-72.

25. Alter M, Talbert OR, Allison RS, Kurland LT. The geographic distribution of multiple sclerosis. A comparative study in Charleston County, South Carolina and Halifax County, Nova Scotia. 1. Prevalence in Charleston County, South Carolina. J S C Med Assoc. 1960 Jun;56:209-13.

26. Stazio A, Kurland LT, Bell LG, Saunders MG, Rogot E. Multiple sclerosis in Winnipeg. Manitoba: methodological considerations of epidemiologic survey. ten year follow-up of a community wide study, and population re-survey. J Chronic Dis. 1964 May; 17:415-38.

27. Bennett L, Hamilton R, Neutel CI, Pearson JC, Talbot B. Survey of persons with multiple sclerosis in Ottawa, 1974-75. Can J Public Health. 1977 Mar-Apr;68(2):141-7.

28. Hader WJ. Prevalence of multiple sclerosis in Saskatoon. Can Med Assoc J. 1982 Aug 15;127(4):295-7.

29. Dyment DA, Willer CJ, Scott B, Armstrong H, Ligers A, Hillert J, Paty DW, et al. Genetic susceptibility to MS: a second stage analysis in Canadian MS families. Neurogenetics 2001;3(3):145-51.

30. Willer CJ, Dyment DA, Risch NJ, Sadovnick AD, Ebers GC Canadian Collaborative Study Group. Twin concordance and sibling recurrence rates in multiple sclerosis. Proc Natl Acad Sci U S A. 2003; $100(22): 12877-82$.

31. Higgins JP, Thompson SG, Deeks JJ, Altman DG. Measuring inconsistency in meta-analyses. BMJ. 2003 Sep 6;327(7414) 557-60.

32. Hatala R, Keitz S, Wyer P, Guyatt G. Tips for learners of evidencebased medicine: 4 . Assessing heterogeneity of primary studies in systematic reviews and whether to combine their results. CMAJ. 2005 Mar 1;172(5):661-5.

33. Cowen JB, Sjostrom BF, Doughty AS, Schiffer RB. Case-finding for MS prevalence studies in small communities requires community-based approach. Neuroepidemiology. 2007;28:24652.

34. Fangerau T, Schimrigk S, Haupts M, Kaeder M, Ahle G, Brune N, Klinkenberg $\mathrm{K}$, et al. Diagnosis of multiple sclerosis: comparison of the Poser criteria and the new McDonald criteris. Acta Neurol Scand. 2004;109(6):385-89

35. Polman CH, Reingold SC, Edan G, Filippi M, Hartung HP, Kappos L, et al. Diagnostic criteria for multiple sclerosis: 2005 revisions to the "McDonald Criteria". Ann Neurol. 2005 Dec;58(6):840-6.

36. McDonald WI, Compston A, Edan G, Goodkin D, Hartung HP Lublin FD, et al. Recommended diagnostic criteria for multiple sclerosis: guidelines from the International Panel on the diagnosis of multiple sclerosis. Ann Neurol. 2001 Jul;50(1): $121-7$

37. Zivadinov R, Iona L, Monti-Bragadin L, Bosco A, Jurjevic A, Taus $C$, et al. The use of standardized incidence and prevalence rates in epidemiological studies on multiple sclerosis. A meta-analysis study, Neuroepidemiology. 2003 Jan-Feb;22(1):65-74.

38. Hader WJ, Irvine DG, Schiefer HB. A cluster-focus of multiple sclerosis at Henribourg, Saskatchewan. Can J Neurol Sci. 1990 Nov; 17(4):391-4.

39. Orton SM, Herrera BM, Yee IM, Valdar W, Ramagopalan SV, Sadovnick AD, Ebers GC. Sex ratio of multiple sclerosis in Canada: a longitudinal study. Lancet Neurol. 2007;5:932-6.

40. Sadovnick AD, Risch NJ, Ebers GC. Canadian collaborative project on genetic susceptibility to MS, phase 2: rationale and method. Can I Neurol Sci. 1998;25:216-21.

41. Warren S, Svenson L, Woodhead S, Warren KG. Parental ancestry and risk of multiple sclerosis in Alberta, Canada. Neuroepidemiology. 1996 Jan-Feb;15(1):1-9.

42. Hostetler J. The Hutterite Society. Baltimore: Johns Hopkins University; 1974.

43. Compston A. Genetic susceptibility to multiple sclerosis. In: Compston A, Ebers G, Lassman H, McDonald I, Matthews B, Werkerle $\mathrm{H}$, editors. McAlpines multiple sclerosis. Edinburgh: Churchill-Livingston; 1998. p. 101-42.

44. Pugliatti M, Rosati G, Carton H, Riise T, Drulovic J, Vecsei L, Milanov I. The epidemiology of multiple sclerosis in Europe. Eur J Neurol. 2006;13:700-22.

45. Vukusic S, Van Bockstael V, Gosselin S, Confavreux C. Regional variations in the prevalence of multiple sclerosis in French farmers. J Neurol Neurosurg Psychiatry. 2007;78:707-9.

46. Coo H, Aronson KJ. A systematic review of several potential nongenetic risk factors for multiple sclerosis. Neuroepidemiology. 2004; 23:1-12.

47. Myhr KM, Grytten N, Aarseth JH, Nyland H. The Norwegian Multiple Sclerosis National Competence Centre and National Multiple Sclerosis registry - a resource for clinical practice and research. Acta Neurol Scan. 2006;183:Suppl. 37-40. 